\title{
Measuring data reliability for preventive services in electronic medical records
}

\author{
Michelle Greiver $^{1 *}$, Jan Barnsley ${ }^{2}$, Richard H Glazier ${ }^{3}$, Bart J Harvey ${ }^{4}$ and Rahim Moineddin ${ }^{5}$
}

\begin{abstract}
Background: Improvements in the quality of health care services are often measured using data present in medical records. Electronic Medical Records (EMRs) contain potentially valuable new sources of health data. However, data quality in EMRs may not be optimal and should be assessed. Data reliability (are the same data elements being measured over time?) is a prerequisite for data validity (are the data accurate?). Our objective was to measure the reliability of data for preventive services in primary care EMRs during the transition to EMR.
\end{abstract}

Methods: Our data sources were randomly selected eligible patients' medical records and data obtained from provincial administrative datasets. Eighteen community-based family physicians in Toronto, Ontario that implemented EMRs starting in 2006 participated in this study. We measured the proportion of patients eligible for a service (Pap smear, screening mammogram or influenza vaccination) that received the service. We compared the change in rates of selected preventive services calculated from the medical record audits with the change in administrative datasets.

Results: In the first year of EMR use (2006) services decreased by $8.7 \%$ more $(95 \% \mathrm{Cl}-11.0 \%--6.4 \%, p<0.0001)$ when measured through medical record audits as compared with administrative datasets. Services increased by $2.4 \%$ more $(95 \% \mathrm{Cl} 0 \%-4.9 \%, p=0.05)$ in the medical record audits during the second year of EMR use (2007).

Conclusion: There were differences between the change measured through medical record audits and administrative datasets. Problems could include difficulties with organizing new data entry processes as well as continued use of both paper and EMRs. Data extracted from EMRs had limited reliability during the initial phase of EMR implementation. Unreliable data interferes with the ability to measure and improve health care quality

Keywords: Measurement, Reliability, Validity, Electronic medical records, Preventive health services, Quality of health care, Primary medical care

\section{Background}

The quality, accuracy and completeness of the information in medical records is fundamental to good patient care and to quality improvement activities: "you cannot improve what you cannot measure" [1]. The transition from paper-based records to Electronic Medical Records (EMRs) has led to expectations that electronic health care data can and will be used to measure and improve the quality of care provided to patients [2,3].

However, the quality of the data entered in EMRs as part of routine care needs to be assessed; missing or inconsistent data may make the measurement of quality

\footnotetext{
* Correspondence: mgreiver@rogers.com

'Department of Family and Community Medicine, University of Toronto,

Duncan Mill Road, Suite 705, Toronto, ON, Canada

Full list of author information is available at the end of the article
}

problematic [4]. Many physicians continue to simultaneously use both paper and electronic medical records, or "hybrid" charts, [5] leading to uncertainty as to where data reside. Problems already encountered in both Canadian and international primary care EMR settings include inconsistent or missing diagnostic coding and risk factor designation, "dirty data" (misspelled words, inconsistent word strings, free text strings instead of structured data), missing "metadata" or description of data content (for example, referral to "Dr Smith", where physician specialty is not listed) and data entered in inconsistent or incorrect database fields [4,6-13].

Data quality factors can be categorized as data completeness (are all the data present?), data reliability (are data recorded in the same way across practices and over time?) and data validity (are the data correct?) $[14,15]$. 
In a recent literature review of EMR data use for health outcome research, only $24 \%$ of studies had a data validation component, and most studies used paper based records as the gold standard [16]. The least common method of validation was the use of administrative data $[16,17]$. The majority of data validation studies were not conducted in the primary care setting [16]. There were difficulties with the reference standards used to evaluate EMR data quality; some studies relied on unvalidated standards (surveys, interviews); current "gold standards" such as paper notes may be problematic $[14,18,19]$. As one editorial noted, "there are no agreed reference standards for reporting data quality in primary care and this limits measurement of data quality in electronic patient records" [20]. While there are many possible ways to measure EMR data quality and many areas that can be measured, $[8,21,22]$ systematic reviews of data quality assessment have noted a focus on diagnostic data, laboratory testing, risk factors and demographic information, with limited information on data quality regarding preventive services $[7,15]$.

We recently studied the effects of the first two years of EMR implementation in the practices of eighteen community-based family physicians in Toronto [23]. We measured preventive services targeted by Ontario's pay for performance program. The pay-for-performance targets were based upon the percentage of a physician's eligible enrolled patients being provided with Pap smears, mammograms, influenza vaccinations, fecal occult blood screening and primary vaccinations of children under two within a specified timeframe [24-26]. We found no difference in the change of service provision between physicians implementing EMR and a group who continued to use paper records [23].

As part of the study, we evaluated aspects of the quality of the data present for those preventive services in the medical records by comparing results obtained from medical record audits against external data sources. The external sources were provincial administrative claims-based data housed at the Institute for Clinical Evaluative Sciences (ICES). ICES is an independent, not-for-profit health services research organization funded by the Ministry of Health and Long Term Care of Ontario. Ontario has population-based coverage for eligible physician, laboratory, diagnostic imaging and hospital services through the Ontario Health Insurance Plan. A copy of fees submitted to the Ministry of Health and Long Term Care of Ontario is maintained in anonymized administrative databases at ICES.

As noted above, medical record reviews and audits have traditionally been considered to be the "gold standard" for certain health care services, and have been used to validate administrative data $[27,28]$. The administrative data we used to determine the rates of preventive services have not been validated using this method. However, we assumed that these administrative data captured a relatively constant proportion of services provided over the time during the period we studied. For example, if $75 \%$ of influenza vaccinations were available in administrative data in 2006, we would expect that approximately $75 \%$ would be available in 2007. We know of no positive or negative changes during the time period studied that would have affected billing proportions captured in administrative databases. We therefore used the change in preventive services reported in the administrative data for the study practices as the reference standard and compared this change to results from the chart audits. This gave us a method of measuring the reliability of data recorded in EMRs over time as compared with administrative data.

Our null hypothesis was that data for preventive services are reliably entered in clinical records over time during EMR implementation; there are no statistically significant or clinically important differences between changes in EMR data and changes in administrative data.

The research question was: does the change in preventive services in medical records before and during the first two years of EMR use agree with the change in preventive services in administrative data?

\section{Methods}

\section{Participants}

The eighteen physicians in this study had previously participated in a pay-for-performance study [29] and data on their characteristics and performance for 2004 and 2005 were available. They changed to a blended capitation model at the end of 2004, in which patients formally register (or roster) with a family physician. These physicians were exposed to pay-for-performance for preventive services in 2005 and began EMR implementation early in 2006. All participating physicians used the same EMR software (Nightingale On Demand ${ }^{\circledR}$ ). We studied the change in preventive services in the two years prior to EMR implementation (2004 and 2005) and the first two years of EMR implementation (2006 and 2007).

The principal investigator was also a participant in this study.

\section{Outcome measures}

The study end point was whether or not a preventive service was documented within the required time period for an eligible patient. The target patient population consisted of all eligible enrolled patients. Documentation that the patient received the service through another health care provider was acceptable. Information on services and exclusion criteria is presented in Table 1; children's vaccinations were not examined, as billing codes in administrative databases also include vaccinations other than the five used in the study. 
Table 1 Eligibility criteria, exclusion criteria, and required period for preventive service provision

\begin{tabular}{|c|c|c|c|}
\hline Service & Eligible population & Exclusion criteria & Required period for service provision \\
\hline Pap smears & Enrolled women age 35 to 69 & Previous hysterectomy & $\begin{array}{l}\text { Documented service within the past } \\
30 \text { months prior to March 31st }\end{array}$ \\
\hline Screening mammograms & Enrolled women age 50 to 69 & History of breast cancer & $\begin{array}{l}\text { Documented service within the past } \\
30 \text { months prior to March 31st }\end{array}$ \\
\hline Influenza vaccination & Enrolled patients age 65 or over & & $\begin{array}{l}\text { Documented service from October 1st } \\
\text { to December } 31 \text { st of previous year }\end{array}$ \\
\hline Fecal occult blood test & Enrolled patients age 50 to 74 & $\begin{array}{l}\text { History of colorectal cancer; history } \\
\text { of inflammatory bowel disease; } \\
\text { colonoscopy within the past five } \\
\text { years }\end{array}$ & $\begin{array}{l}\text { Documented service in the past } \\
30 \text { months prior to March 31st }\end{array}$ \\
\hline
\end{tabular}

"The fiscal year end in Ontario's health care system is March 31st. For example, March 31st 2007 would be considered the 2006 year end, and March 31 st 2008 would be considered the 2007 year end.

The denominators were the number of patients eligible for each service who were rostered to the physicians in each cohort by March 31st of each fiscal year (for example, March 31st 2005 for the 2004 fiscal year). Physicians report the preventive service performance levels they have achieved to the Ministry of Health and Long Term Care on March 31st.

The numerators were the number of eligible rostered patients who received a service in the 30 months prior to March 31st of each year for Pap smears, mammograms or fecal occult blood testing, or an influenza vaccination from October 1st to December 31st of the prior year. The rate of service was defined as the proportion of eligible patients receiving a service at least once in the previous 30 months (Pap smears, mammograms, fecal occult blood tests) or in the previous fall (October 1st to December 31st) for influenza vaccination.

We calculated a composite process score [30]. This is calculated by using the total number of medical records audited for eligible patients for each physician as the denominator, and the total number of services recorded in the audits as the numerator. We did not obtain fecal occult blood testing for 2004 as part of our previous study on pay for performance; fecal occult blood testing was not part of the Ontario pay for performance program until 2006. This measure was not included in the composite score due to lack of complete data. The composite process score therefore included mammography, Pap smears and influenza vaccinations from 2004 to 2007.

\section{Data sources}

\section{Chart audits}

We primarily audited the electronic medical records. However, when data were unavailable in an EMR, we retrieved data from the paper chart. We determined that 40 charts per service per provider would be required to achieve a study power of $80 \%$ to detect a clinically important increase in service provision of $5 \%$ or higher, with an alpha level of .05. To further enhance statistical power, we audited 50 charts per year, per service, per physician.

Five data auditors abstracted data. The research coordinator initially audited ten charts for each service in two practices and reviewed this with the principal investigator. The coordinator then trained each data auditor, and reviewed at least ten charts for each service. The data were independently entered in an Epi Info database [31] by two data entry clerks. Each clerk entered a training sample of at least ten charts for each service. A randomly selected $10 \%$ sample of data for each service, each year, and each physician was re-audited and entered in the database; we used the Kappa statistic to compare the two audits.

\section{Administrative audits}

We obtained administrative data for the entire practices from ICES, using the following datasets:

- The ICES Physician Database (IPDB) for information on physician country of graduation;

- The Corporate Provider Database (CPDB) for information on physicians' Ontario Health Insurance Plan billing number;

- The Ontario's Registered Persons Database (RPDB) for patient age (as of August 31st 2007), gender and immigration recency by date of OHIP registration [32];

- The Client Agency Program Enrolment (CAPE) tables for information on patient enrolment in each physician's roster;

- Statistics Canada data on neighborhood income, linked to patients' residential postal code for estimates of income quintiles [32];

- The Canadian Institute for Health Information's Discharge Abstract Database for hospital discharge diagnoses;

- The Ontario Health Insurance Plan for billing and diagnostic data to identify patient visits and diagnoses;

- The Ontario Diabetes Database (ODD) for diabetics [28]; 
- The Ontario Asthma Database (OASIS) [33];

- The Ontario Congestive Heart Failure Database [34];

- The Ontario Chronic Obstructive Pulmonary Disease Database [35];

- The Ontario Hypertension Database [27];

- The Ontario Myocardial Infarction Database [36];

- The Ontario Cancer registry for information on breast or colorectal cancer

- The Ontario Breast Screening Program (OBSP) for information on mammography

A detailed description of the billing codes for the administrative data is provided in Additional file 1.

\section{Analysis}

We first calculated the composite process score for each year, for both medical record audits and administrative data. An equal number of charts had been randomly audited for each service in the medical record; we therefore assigned an equal weight to each service in the administrative dataset (which contained data for the entire practice) for the composite score calculation. We then adjusted for differences in patient age [37] using logistic regression. We used the Generalized Estimating Equation to adjust for the clustering structure of the data in regression models.

Next, we compared the composite process score found in medical record audits and administrative data for each year using the chi-square test. We then compared the year over year change in the composite process score (that is, the percent of change found in the medical record audits and the percent of change found in the administrative data) using logistic regression.

A difference of $5 \%$ in the change of services between medical record audits and administrative data was considered clinically important.

Analyses were performed with the use of SAS software, version 9.2 (SAS Institute). All tests were two sided and $\mathrm{p}$ values less than 0.05 were considered statistically significant.
The study was approved by the University of Toronto's Research Ethics Board; the Sunnybrook Research Ethics Board approved the use of ICES data. All physicians provided written informed consent.

\section{Results}

Physician characteristics and patient characteristics are presented in Table 2 and 3, respectively.

A comparison of the composite scores obtained from the medical record audits and from administrative data is presented in Table 4 . There was a statistically significant greater increase of $4.2 \%$ (95\% CI $2.0 \%-6.4 \%)$ in the change in services found in medical record audits following the introduction of pay for performance in 2005 . However, this did not reach the previously identified clinically important level of $5 \%$. There was a statistically significant and clinically important larger decrease in services in the first year of EMR when these services were measured using medical record audits rather than administrative data. Measured services declined by $8.7 \%$ (95\% CI $-11.0 \%--6.4 \%)$ more when measured by medical record audits. There was no statistically significant or clinically important difference in change in the following year

There was a significantly smaller proportion of services found in the medical record audits as compared with the administrative data in the year that the EMR was introduced (2006). There were more services found in the medical record audits for the two years prior to EMR (2004 and 2005), and no difference was found in the following year (2007).

Table 5 presents data for individual services derived from medical record audits and administrative data. These are presented graphically in Figure 1 (for Pap smears and mammograms) and Figure 2 (for influenza vaccinations and fecal occult blood tests).

The intracluster correlation for each service in medical record audits was generally small, at 0.036 for influenza vaccination, 0.0197 for fecal occult blood testing, 0.0189 for mammography, and 0.009 for Pap smears. Increasing

Table 2 Characteristics of physicians

\begin{tabular}{lll}
\hline Variable & & Physicians (N= 18) \\
\hline Year of graduation* & Median (range) & $1977(1964-1992)$ \\
Gender* & Male (\%) & $10(56)$ \\
CCFP* & $N(\%)$ & $11(61)$ \\
Number of MDs in practice* & Median (range) & $3(1$ to 6) \\
Number of hours worked per week* & Median (range) & $42(30$ to 60) \\
Number of patients per physician* & Median (range) & $1206(630-2200)$ \\
Canadian vs foreign graduatet & & $16 / 18$ \\
\hline
\end{tabular}

Note: CCFP Certificant of the College of Family Physicians of Canada.

*Obtained from self reports.

tObtained from administrative databases. 
Table 3 Characteristics of the total practice population

\begin{tabular}{|c|c|c|}
\hline \multicolumn{3}{|l|}{ Variable $^{*}$} \\
\hline Patients & N (Mean) & $23,514(1,306)$ \\
\hline Age as of August 31st 2007 & Median (IQR) & $45(27-60)$ \\
\hline Patient Gender & Male (\%) & $10,106(43.0)$ \\
\hline \multicolumn{3}{|l|}{ Neighbourhood income quintile [32] } \\
\hline Unknown & $N(\%)$ & $51(0.2)$ \\
\hline 1 (lowest) & $N(\%)$ & $3,084(13.1)$ \\
\hline 2 & $N(\%)$ & $3,643(15.5)$ \\
\hline 3 & N (\%) & $4,345(18.5)$ \\
\hline 4 & N (\%) & $5,091(21.7)$ \\
\hline 5 (highest) & $N(\%)$ & $7,300(31.0)$ \\
\hline Recent immigrant [32] & & $1,398(5.9)$ \\
\hline Comprehensiveness of care ${ }^{\dagger}[32,38]$ & Mean \pm SD & $0.54 \pm 0.35$ \\
\hline Overall morbidity (Resource Utilization Bands) ${ }^{\frac{1}{\star}}[39,40]$ & Mean \pm SD & $2.73 \pm 1.02$ \\
\hline 0 & N (\%) & $1,047(4.5)$ \\
\hline 1 & $N(\%)$ & $1,480(6.3)$ \\
\hline 2 & N (\%) & $4,778(20.3)$ \\
\hline 3 & $N(\%)$ & $12,567(53.4)$ \\
\hline 4 & $N(\%)$ & $2,783(11.8)$ \\
\hline 5 & N (\%) & $859(3.7)$ \\
\hline Overall comorbidity (Adjusted Diagnosis Groups) ${ }^{\S}[39,40]$ & Mean $\pm S D$ & $4.77 \pm 3.04$ \\
\hline 0 & $N(\%)$ & $1,046(4.4)$ \\
\hline $1-4$ & $N(\%)$ & $11,189(47.6)$ \\
\hline $5-9$ & $N(\%)$ & $9,502(40.4)$ \\
\hline $10+$ & $N(\%)$ & $1,777(7.6)$ \\
\hline Diabetes [28] & N (\%) & $1,934(8.2)$ \\
\hline Congestive heart failure [34] & N (\%) & $386(1.6)$ \\
\hline Hypertension [27] & $N(\%)$ & $5,594(23.8)$ \\
\hline Myocardial infarct [36] & $N(\%)$ & $311(1.3)$ \\
\hline Asthma [33] & $N(\%)$ & $3,143(13.4)$ \\
\hline Chronic obstructive pulmonary disease [35] & N (\%) & $1,120(4.8)$ \\
\hline Mental health [41] & $N(\%)$ & $4,937(21.0)$ \\
\hline
\end{tabular}

Note: $I Q R$ interquartile range; $S D$ standard deviation.

* Obtained from administrative databases.

${ }^{+}$Comprehensiveness of care was determined by measuring the percentage of bills for 21 commonly provided services that were provided by the patient's own family physician.

\$ Resource utilization bands indicate morbidity and expected health care system use, from 0 (lowest) to 5 (highest).

${ }^{\S}$ Adjusted diagnosis groups indicate comorbidity, from 0 groups (lowest level of comorbidity) to 10+ groups (highest level).

patient age was a significant factor for the provision of a preventive service (data not shown). Using medical record audits, there was a decrease in the provision of mammograms, pap smears and influenza vaccinations between 2005 and $2006(p<0.001)$; there was no significant change in fecal occult blood testing $(p=0.12)$.

Administrative data showed no significant change between 2005 and 2006 for Pap smears $(p=0.52)$ or mammography $(p=0.48)$; there was a decrease in influenza vaccination $(p<0.0001)$ and an increase in fecal occult blood testing $(p<0.0001)$.

The overall agreement between the sample of medical records that were re-audited was acceptable (kappa 0.954).

\section{Discussion}

We present a novel method of assessing an aspect of EMR data quality. We compared the rate of change of services over time in the EMR with the rate of change in 
Table 4 Comparison of medical record audits and administrative data, composite score for mammography, Pap smears and influenza vaccinations

\begin{tabular}{|c|c|c|c|c|}
\hline Year & $\begin{array}{l}\text { Patients } \\
\text { receiving service, } \\
\text { medical record } \\
\text { audits, } \mathrm{n} / \mathrm{N}, \\
\%(95 \% \mathrm{Cl})^{*}\end{array}$ & $\begin{array}{l}\text { Patients receiving } \\
\text { service, } \\
\text { administrative } \\
\text { data, } \mathrm{n} / \mathrm{N} \text {, } \\
\%(95 \% \mathrm{Cl})\end{array}$ & $\begin{array}{l}\text { Difference } \\
\text { between } \\
\text { medical record } \\
\text { audits and } \\
\text { administrative } \\
\text { data within } \\
\text { year }(95 \% \mathrm{Cl})\end{array}$ & $\begin{array}{l}\text { Difference in the } \\
\text { change from } \\
\text { previous year } \\
(95 \% \mathrm{Cl})\end{array}$ \\
\hline 2004 & $2264 / 2807,80.7 \%(79.2 \%-82.1 \%)$ & $11074 / 14096,78.6 \%(77.9 \%-79.2 \%)$ & $+2.1 \%(0.5 \%-3.7 \%)$ & \\
\hline $\begin{array}{l}2005 \text { (post pay-for- } \\
\text { performance) }\end{array}$ & $2385 / 2809,84.9 \%(83.6 \%-86.2 \%)$ & $11735 / 14927,78.6 \%(78.0 \%-79.3 \%)$ & $+6.3 \%(4.8 \%-7.8 \%)$ & $\begin{array}{l}4.2 \% \text { greater increase } \\
\text { with chart audits }(2.0 \%-6.4 \%)\end{array}$ \\
\hline $\begin{array}{l}2006 \text { (first year } \\
\text { after EMR introduction) }\end{array}$ & 1995/2696,74.1\%(72.4\%-75.7\%) & 11692/15291,76.5\%(75.8\%-77.1\%) & $-2.4 \%(-4.2 \%--0.6 \%)$ & $\begin{array}{l}8.7 \% \text { greater decrease } \\
\text { with chart audits } \\
(-11.0 \%--6.4 \%)\end{array}$ \\
\hline $\begin{array}{l}2007 \text { (second year } \\
\text { after EMR introduction) }\end{array}$ & 2076/2703,77.2\%(75.6\%-78.8\%) & $12005 / 15559,77.2 \%(76.5 \%-77.8 \%)$ & $0(-1.7 \%-1.8 \%)$ & $\begin{array}{l}2.4 \% \text { greater increase } \\
\text { with chart audits(0\%-4.9\%) }\end{array}$ \\
\hline
\end{tabular}

*Percentages are adjusted for patient age.

administrative databases. We found a greater decrease in preventive services in the first year of EMR when data were obtained from medical record audits as opposed to administrative data sources. The discrepancy between the two methods points to the possibility of missing data for preventive services in the medical records.

Reliability reflects data stability, and is necessary (but not sufficient) for data validity [15]. Our administrative data for Pap smears were based on billing codes submitted by laboratories and physician billing codes as detailed in Additional file 1. Laboratory billings would not have been affected by EMR implementation. Administrative data for mammograms were based on radiology billing codes and data from the Ontario Breast Screening Program, as shown in Additional file 1. These also were independent of EMR implementation.

The change in influenza vaccinations was similar in the medical record audits and in the administrative data, perhaps reflecting fewer problems with documentation. Documenting an influenza vaccination does not require looking two years back for the presence of the service, as mammography or Pap smears do; therefore, there may be a less complex workflow associated with recording this service during the move to EMR. There were delays in vaccine delivery in 2006 and 2007, which could account for the lower levels of vaccination found in both the medical record audits and the administrative data during the fall season of those two years.

Challenges with the data needed to measure quality have been reported elsewhere in the literature $[7,8,11,14,15]$. Roth [42] found that only one-third of the indicators needed for a quality assessment program could be easily extracted from EMRs, and that there were difficulties associated with provider data entry habits and differences across different EMR applications [42]. The structure of the EMR is more complex than that of the paper chart: physicians may not be entering data in consistent or expected locations, making it difficult to extract [42]. Physicians and auditors may have challenges in navigating the electronic medical record. Data from external sources may be scanned in and may not be extractable electronically [43]. Physicians may continue to use both paper and electronic medical records, [5] scattering data across two different systems and possibly increasing the amount of incomplete or duplicated data in audits. Research and quality improvement projects using EMR data will need to consider the quality of data entered in the EMR, as well as issues specific to the EMR application used [42].

Table 5 Individual services levels derived from medical records audits and from administrative data

\begin{tabular}{|c|c|c|c|c|c|}
\hline Service & Source & 2004 & 2005 & 2006 & 2007 \\
\hline Fecal occultblood tests,\% (n/N) & Administrativedata & $21.7 \%(5139 / 1117)$ & $23.2 \%(1216 / 5239)$ & $23.6 \%(1232 / 5216)$ & $26.4 \%(1355 / 5137)$ \\
\hline Fecal occultblood tests,\% (n/N) & Medical records & - & $27.1 \%(236 / 871)$ & $28.7 \%(250 / 870)$ & $32.1 \%(285 / 888)$ \\
\hline Influenza vaccinations,\% (n/N) & Administrativedata & $74.2 \%(3163 / 4263)$ & $69.5 \%(3095 / 4453)$ & $62.6 \%(2880 / 4601)$ & $64.3 \%(3072 / 4776)$ \\
\hline Influenza vaccinations,\% (n/N) & Medical records & $76.2 \%(745 / 978)$ & $83.2 \%(790 / 949)$ & $70.7 \%(638 / 902)$ & $69.8 \%(621 / 901)$ \\
\hline Mammograms,\% (n/N) & Administrativedata & $79.3 \%(2671 / 3367)$ & $81.3 \%(3095 / 4453)$ & $82.0 \%(3026 / 3692)$ & $82.8 \%(3072 / 4776)$ \\
\hline Mammograms,\% (n/N) & Medical records & $81.9 \%(751 / 917)$ & $85.4 \%(791 / 926)$ & $75.2 \%(672 / 894)$ & $80.9 \%(728 / 900)$ \\
\hline Pap smears,\% (n/N) & Administrativedata & $81.0 \%(5240 / 6466)$ & $83.1 \%(5736 / 6903)$ & $82.7 \%(5786 / 6998)$ & $82.9 \%(5807 / 7007)$ \\
\hline Pap smears,\% (n/N) & Medical records & $84.2 \%(768 / 912)$ & $86.1 \%(804 / 934)$ & $76.1 \%(685 / 900)$ & 79.7\%(719/902) \\
\hline
\end{tabular}




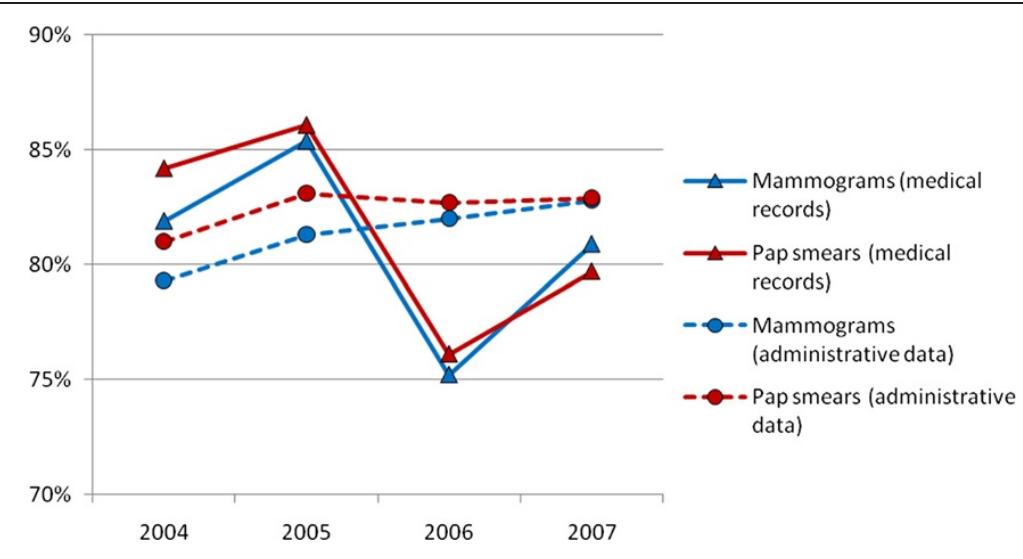

Figure 1 Mammogram and Pap smear service levels derived from medical record audits and from administrative data.

Baron described the implementation of a mammography recall program within an innovative, fully computerized primary care group practice [43]. The system was initially unable to properly audit mammograms and to produce accurate lists of patients to be recalled; mammograms were scanned in but were not recognized by the EMR. Baron described the development and implementation of practice processes to "tag" incoming mammograms so that patients could be properly categorized as having or not having had a mammogram within the previous two years [43]. Essentially, the practice cleaned and restructured their mammography data so that data were reliably entered in an area of the EMR where they could be audited.

The quality of information (accuracy, reliability, completeness) has been found to be associated with empirical measures of success in implementing information technology in the business literature [44]. Unreliable information makes a system less useful, impacting implementation efforts and decreasing the net benefits that could be obtained from the technology [45].

Measuring performance depends on accurate documentation $[1,46,47]$. Once reliable and valid data have been entered into the EMR, interventions that have been found to increase performance, such as audits and feedback to clinicians, $[48,49]$ point of care prompts for needed interventions, [49-51] and reminder letters to patients $[52,53]$ can be effectively implemented. We found a lack of improvement in preventive service documentation associated with the early stages of EMR implementation [23]. It is possible that elements of those negative results were due to problems with data quality during the early EMR implementation efforts.

\section{Limitations}

This study was limited to a group of selected physicians in Toronto. However, all physicians in this study were

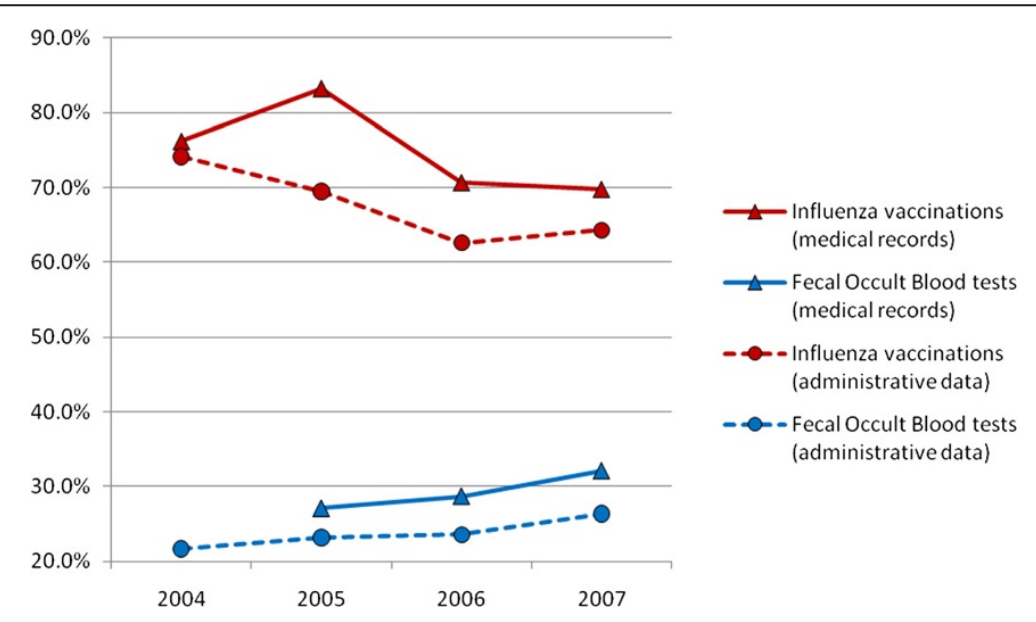

Figure 2 Influenza vaccination and fecal occult blood service levels derived from medical record audits and from administrative data. 
practicing in community-based settings, similar to the majority of family physicians in Ontario [54]. We studied a single commercially available EMR application, and results may differ for different EMRs. Nonetheless, a recent review of data in a national primary care EMR database using nine different EMR applications found that data quality problems were pervasive across all platforms [4]. Administrative data and patient level data in the EMR could not be linked; we compared practice level data using randomly selected EMR charts. Nonetheless, there is no a priori reason to suspect that there are systematic differences between the two samples.

\section{Conclusion}

In conclusion, we found that, in the early phase of EMR implementation, data for the preventive services we measured were not reliably entered over time in the medical records we audited when compared to provincial administrative data. Data reliability should be assessed if EMR-based data are used to measure and improve quality.

\section{Additional file}

Additional file1: Inclusion and exclusion criteria for administrative cohorts.

\section{Competing interests}

The authors declare that they have no competing interests.

\section{Authors' contributions}

All authors contributed to the concept and design of the study. MG and JB contributed to the data gathering. All authors contributed to the analysis, interpretation and preparation of the manuscript. All authors read and approved the final manuscript.

\section{Acknowledgements}

This study was funded by a research grant from the Ontario Ministry of Health and Long Term Care Health System Strategy Division (Grant No 020709).

This study was also supported by the Institute for Clinical Evaluative Sciences (ICES), which is funded by an annual grant from the Ontario Ministry of Health and Long-Term Care (MOHLTC). The opinions, results and conclusions reported in this paper are those of the authors and are independent from the funding sources. No endorsement by ICES or the Ontario MOHLTC is intended or should be inferred.

\section{Author details \\ ${ }^{1}$ Department of Family and Community Medicine, University of Toronto, Duncan Mill Road, Suite 705, Toronto, ON, Canada. ${ }^{2}$ Department of Health Policy, Management \& Evaluation, University of Toronto, Institute for Clinical Evaluative Sciences, Toronto, Canada. ${ }^{3}$ Department of Family and Community Medicine, Institute for Clinical Evaluative Sciences, Centre for Research on Inner City Health, St. Michael's Hospital, University of Toronto, Toronto, Canada. ${ }^{4}$ Dalla Lana School of Public Health, University of Toronto, Toronto, Canada. ${ }^{5}$ Department of Family and Community Medicine, University of Toronto, Institute for Clinical Evaluative Sciences, Dalla Lana School of Public Health, Toronto, Canada.}

\section{References}

1. Newcomer LN: Perspective: physician, measure thyself. Health Aff 1998, 17 (4):32-35.

2. Romanow R: Building on values: the future of health care in Canada. Ottawa: National Library of Canada; 2002.

3. Have paper records passed their expiry date? CMAJ 2005, 173(7):725.

4. CIHI CPCSSN data analysis report: cycle 2A. Toronto: Canadian Institutes for Health Information; 2010

5. National Physician Survey. [http://www.nationalphysiciansurvey.ca/nps/ 2007 Survey/2007results-e.asp].

6. Birtwhistle R, Keshavjee K, Lambert-Lanning A, Godwin M, Greiver M, Manca $D$, Lagace C: Building a pan-Canadian primary care sentinel surveillance network: initial development and moving forward. J Am Board Fam Med 2009, 22(4):412-422.

7. Brouwer $\mathrm{H}$, Bindels $\mathrm{P}$, Weert $\mathrm{H}$ : Data quality improvement in general practice. Fam Pract 2006, 23(5):529-536.

8. Whitelaw FG, Nevin SL, Milne RM, Taylor RJ, Taylor MW, Watt AH: Completeness and accuracy of morbidity and repeat prescribing records held on general practice computers in Scotland. Br J Gen Pract 1996, 46 (404):181-186.

9. Selak V, Wells S, Whittaker R, Stewart A: Smoking status recording in GP electronic records: the unrealised potential. Inform Prim Care 2006, 14 (4):235-241. discussion 242-235.

10. Mant J, Murphy M, Rose $\mathrm{P}$, Vessey M: The accuracy of general practitioner records of smoking and alcohol use: comparison with patient questionnaires. J Pub Health Med 2000, 22(2):198-201.

11. Hollowell J: The General Practice Research Database: quality of morbidity data. Popul Trends 1997, 87:36-40.

12. Mukhi S, Keshavjee K: Developing a primary care electronic medical record chronic disease surveillance system in Canada: data quality and lessons learned. Calgary: In Canadian Association of Health Services and Policy Research; 2009.

13. Birtwhistle R, Keshavjee K, Martin K: Improving data quality in EMRs for chronic disease management. In Family Medicine Forum. Calgary: LambertLanning A; 2009.

14. Chan KS, Fowles JB, Weiner JP: Review: electronic health records and the reliability and validity of quality measures: a review of the literature. Med Care Res Rev 2010, 67(5):503-527.

15. Thiru K, Hassey A, Sullivan F: Systematic review of scope and quality of electronic patient record data in primary care. BMJ 2003, 326(7398):1070

16. Dean BB, Lam J, Natoli JL, Butler Q, Aguilar D, Nordyke RJ: Review: use of electronic medical records for health outcomes research: a literature review. Med Care Res Rev 2009, 66(6):611-638.

17. Benin AL, Vitkauskas G, Thornquist E, Shapiro ED, Concato J, Aslan M Krumholz HM: Validity of using an electronic medical record for assessing quality of care in an outpatient setting. Med Care 2005, 43(7):691-698.

18. Tang PC, LaRosa MP, Gorden SM: Use of computer-based records, completeness of documentation, and appropriateness of documented clinical decisions. J Am Med Inform Assoc 1999, 6(3):245-251.

19. Jordan $K$, Porcheret $M$, Croft P: Quality of morbidity coding in general practice computerized medical records: a systematic review. Fam Pract 2004, 21(4):396-412

20. Majeed A, Car J, Sheikh A: Accuracy and completeness of electronic patient records in primary care. Fam Pract 2008, 25(4):213-214

21. Jick H, Jick SS, Derby LE: Validation of information recorded on general practitioner based computerised data resource in the United Kingdom. BMJ 1991, 302(6779):766-768.

22. Porcheret M, Hughes R, Evans D, Jordan $K$, Whitehurst T, Ogden H, Croft P, North Staffordshire General Practice Research N: Data quality of general practice electronic health records: the impact of a program of assessments, feedback, and training. J Am Med Inform Assoc 2004, 11(1):78-86

23. Greiver M, Barnsley J, Glazier R, Harvey B, Moineddin R: Effect of electronic medical record implementation on the provision of preventive services in a pay for performance environment. Canadian Family Physician 2011, 57:e390-e397.

24. Family health network agreement: General blended payment template. Ministry of Health and Long Term Care of Ontario and the Ontario Family Health Network Corporation; 2002.

25. Memorandum of agreement between the Ontario Medical Association and the Ontario Ministry of Health and Long Term Care. Toronto: Government of Ontario; 2004. 
26. Memorandum of agreement between the Ontario Medical Association and the Ontario Ministry of Health and Long Term Care. Toronto: Government of Ontario; 2003.

27. Tu K, Campbell NR, Chen ZL, Cauch-Dudek KJ, McAlister FA: Accuracy of administrative databases in identifying patients with hypertension. Open Med 2007, 1(1):e18-e26.

28. Hux JE, Ivis F, Flintoft V, Bica A: Diabetes in Ontario: determination of prevalence and incidence using a validated administrative data algorithm. Diabetes Care 2002, 25(3):512-516.

29. Greiver M, Kasperski J, Barnsley J, Rachlis V: Measuring quality improvements in preventive care services in the first two family health networks in the greater Toronto area. Toronto: Ontario College of Family Physicians; 2006.

30. Lindenauer PK, Remus D, Roman S, Rothberg MB, Benjamin EM, Ma A, Bratzler DW: Public reporting and pay for performance in hospital quality improvement. N Engl J Med 2007, 356(5):486-496.

31. Epi Info. 332nd edition. Atlanta: Centers for Disease Control and Prevention; 2005

32. Glazier RH, Klein-Geltink J, Kopp A, Sibley LM: Capitation and enhanced fee-for-service models for primary care reform: a population-based evaluation. CMAJ 2009, 180(11):E72-E81.

33. Gershon AS, Wang C, Guan J, Vasilevska-Ristovska J, Cicutto L, To T: Identifying patients with physician-diagnosed asthma in health administrative databases. Can Respir J 2009, 16(6):183-188.

34. Ko DT, Alter DA, Austin PC, You JJ, Lee DS, Qiu F, Stukel TA, Tu JV: Life expectancy after an index hospitalization for patients with heart failure: a population-based study. Am Heart J 2008, 155(2):324-331.

35. Gershon AS, Wang C, Guan J, Vasilevska-Ristovska J, Cicutto L, To T: Identifying individuals with physcian diagnosed COPD in health administrative databases. COPD 2009, 6(5):388-394.

36. Jackevicius CA, Li P, Tu JV: Prevalence, predictors, and outcomes of primary nonadherence after acute myocardial infarction. Circulation 2008, 117(8):1028-1036.

37. Asch SM, Kerr EA, Keesey J, Adams JL, Setodji CM, Malik S, McGlynn EA: Who is at greatest risk for receiving poor-quality health care? N Engl J Med 2006, 354(11):1147-1156.

38. Shortell SM: Continuity of medical care: conceptualization and measurement. Med Care 1976, 14(5):377-391.

39. The Johns Hopkins University ACG Case-Mix Adjustment System: Baltimore. Md: Johns Hopkins University School of Hygiene and Public Health; 1997.

40. The Johns Hopkins University ACG Case-Mix System. [http://www.acg.jhsph. edu/html/HowDoACGsWork.htm].

41. Steele LS, Glazier RH, Lin E, Evans M: Using administrative data to measure ambulatory mental health service provision in primary care. Med Care 2004, 42(10):960-965.

42. Roth CP, Lim YW, Pevnick JM, Asch SM, McGlynn EA: The challenge of measuring quality of care from the electronic health record. Am J Med Qual 2009, 24(5):385-394.

43. Baron RJ: Quality improvement with an electronic health record achievable, but not automatic. Ann Intern Med 2007, 147(8):549-552.

44. DeLone WH, McLean ER: Information systems success: the quest for the dependent variable. Inform Syst Res 1992, 3(1):60-95.

45. Delone WH, McLean ER: The DeLone and McLean model of information systems success: a ten-year update. J Manage Inf Syst 2003, 19(4):9-30.

46. Chassin MR, Galvin RW, The National Roundtable on Health Care Quality: The urgent need to improve health care quality: Institute of Medicine National Roundtable on Health Care Quality. JAMA 1998, 280(11):1000-1005.

47. Casalino L, Gillies RR, Shortell SM, Schmittdiel JA, Bodenheimer T, Robinson JC, Rundall T, Oswald N, Schauffler H, Wang MC: External incentives, information technology, and organized processes to improve health care quality for patients with chronic diseases. Jama 2003, 289(4):434-441.

48. Perlin JB, Kolodner RM, Roswell RH: The Veterans Health Administration: quality, value, accountability, and information as transforming strategies for patient-centered care. Am J Manag Care 2004, 10(11 Pt 2):828-836.

49. Craig TJ, Perlin JB, Fleming BB: Self-reported performance improvement strategies of highly successful veterans health administration facilities. Am J Med Qual 2007, 22(6):438-444

50. Balas EA, Weingarten S, Garb CT, Blumenthal D, Boren SA, Brown GD: Improving preventive care by prompting physicians. Arch Intern Med 2000, 160(3):301-308.

51. Garg AX, Adhikari NKJ, McDonald H, Rosas-Arellano MP, Devereaux PJ, Beyene J, Sam J, Haynes RB: Effects of computerized clinical decision support systems on practitioner performance and patient outcomes: a systematic review. JAMA 2005, 293(10):1223-1238.

52. Szilagyi PG, Bordley C, Vann JC, Chelminski A, Kraus RM, Margolis PA, Rodewald LE: Effect of patient reminder/recall interventions on immunization rates: a review. Jama 2000, 284(14):1820-1827.

53. Stone EG, Morton SC, Hulscher ME, Maglione MA, Roth EA, Grimshaw JM Mittman BS, Rubenstein LV, Rubenstein LZ, Shekelle PG: Interventions that increase use of adult immunization and cancer screening services: a meta-analysis. Ann Intern Med 2002, 136(9):641-651.

54. Schultz SETJ, Guttmann A, Jaakkimainen L: In Characteristics of primary care practice, Primary care in Ontario: ICES Atlas. Edited by Jaakkimainen LUR, Klein-Geltink JE, Leong A, Maaten S, Schultz SE, Wang L. Toronto: Institute for Clinical Evaluative Sciences; 2006.

doi:10.1186/1472-6963-12-116

Cite this article as: Greiver et al:: Measuring data reliability for preventive services in electronic medical records. BMC Health Services Research 2012 $12: 116$.

\section{Submit your next manuscript to BioMed Central and take full advantage of:}

- Convenient online submission

- Thorough peer review

- No space constraints or color figure charges

- Immediate publication on acceptance

- Inclusion in PubMed, CAS, Scopus and Google Scholar

- Research which is freely available for redistribution 